dangerous, he conducted on himself. No wonder that when the well-known Russian physiologist, A. Samoilov, urged young research workers to investigate directly the human organism, he always referred to Haldane's successful experiments.
Some of the members of the U.S.S.R.-Britain Society prepared for the jubilee meeting an exhibit with the portraits of Bayliss and Haldane and a display of Russian translations of their books.

\title{
IS HYPERCONJUGATION NECESSARY?
}

M ULLIKEN, Reike and Brown ${ }^{1}$ proposed a new type of conjugation, 'hyperconjugation', based on the fact that the heat of hydrogenation of an olefin is appreciably decreased by the presence of alkyl substituents on the unsaturated carbon atom. A necessary effect of hyperconjugation would be to change the lengths of the $\mathrm{C}-\mathrm{H}$ bond in the alkyl group and the $\mathrm{C}-\mathrm{C}$ bond adjacent to a double or triple bond. The $\mathrm{C}-\mathrm{Me}$ distance in toluene ${ }^{2}$ is $1.51 \AA$. and in methyl acetylene and acetonitrile ${ }^{3}$ it is $1.46 \AA$., compared with the normal $\mathrm{C}-\mathrm{C}$ distance of $1.54 \AA$. in ethane. It was pointed out that part of these bond shortenings was due to the change in the atomic radius from tetrahedral to trigonal or digonal carbon and about one-half of the observed shortening was due to hyperconjugation ${ }^{4}$.

Hyperconjugation was considered to be responsible for the dipole moment of alkyl benzenes. The ionization potentials of methylated ethylenes,$^{4}$, and the absorption spectra ${ }^{5,6}$ were also given as evidence for hyperconjugation. The view that $\mathrm{C}-\mathrm{H}$ hyperconjugation is the predominant mode of electron release by alkyl substituents when attached to an electron-demanding system was originally proposed by Baker and Nathan as an explanation of certain rate and equilibrium data. The Baker-Nathan effect was in the order $\mathrm{Me}>\mathrm{E} t>i-\mathrm{Pr}>t-\mathrm{Bu}$, which is exactly the reverse of what one would expect if the electron release were by the inductive mechanism.

Although a great deal of physical and chemical evidence has been accumulated in support of the idea of hyperconjugation, recently there have been a number of observations which cannot be explained in a simple fashion by hyperconjugation, and the situation has become controversial.

Recent molecular structure investigations $s^{3,7}$ in several laboratories, on derivatives of acetonitrile and methyl acetylene, have conclusively shown that the length of a carbon-carbon single bond adjacant to a triple bond (that is, a bond between $s p$ and $s p^{3}$ carbon atoms) is always close to $1.46 \AA$., independent of the substituents on the $s p^{3}$ carbon. So it is concluded that the shortenings in the $\mathrm{C}-\mathrm{C}$ bonds between $s p$ and $s p^{3}$ carbon atoms $\left(0.08 \AA\right.$.) or $s p^{2}$ and $s p^{3}$ carbon atoms $(0.04 \AA$.) may not result from any kind of conjugation, and that it is likely that these bond contractions are entirely due to the changes in the covalent radius of carbon with hybridization. The bond-lengths in relation to hyperconjugation have been discussed in fair detail by Sutton ${ }^{8}$. The evidence for hyperconjugation from calorimetric data is no longer valid, since the change in the $\mathrm{C}-\mathrm{C}$ bond energies with bond-lengths (that is, with hybridization) was not taken into account in these calculations. So the effects attributed to hyperconjugation of the alkyl groups may equally be due to the introduction of a stronger $\mathrm{C}-\mathrm{C}$ bond. In general, the stabilization of an unsaturated system by alkyl substitution has been found to be essentially inde- pendent of the nature of the alkyl group and cannot be escounted for in terms of steric effects ${ }^{9}$.

The evidence for hyperconjugation from dipole moment data also necds to be re-interpreted. Since the electronegativity of an $s p$ or $s p^{2}$ carbon is different from that of an $s p^{3}$ carbon, the resulting bonds (between any two differently hybridized carbon atoms) should have different polarities. In fact, Petro $^{10}$ hes reported excellent agreement between the observed and calculated dipole moments of $\mathrm{C}-\mathrm{C}$ bonds between two differently hybridized carbon atoms. He concludes that hyperconjugation structures do not explain the non-zero dipole moment of toluene. Recently, Brown ${ }^{11}$ has studied the dipole moments of alkyl benzenes and the results are not conclusive.

The earlier evidence for hyperconjugation on the basis of ionization potentials and absorption spectra was not unambiguous because these deal with both the electronic ground-states and the excited states of molecules. The ionization potentials of the alkyl groups are actually found to be in the inductive order ${ }^{2}$. However, a simple molecular orbital treatment by Streitwieser and Nair ${ }^{13}$ seems to indicate that the methyl group can be treated as a 'heteroatom' donating two electrons to the $\pi$-system. The evidence from absorption spectra has met with a number of objections ${ }^{14-16}$. An explanation based on steric hindrance to solvation of the electron-deficient sites in the vicinity of the alkyl substituent has been suggested.

In general, it may be said that the effect of alkyl groups on the near ultra-violet absorption spectra of aromatic compounds is not consistent. A recent study of the $n \rightarrow \pi^{*}$ transitions of aliphatic ketones and nitro compounds in different types of solvents by Rao et al. ${ }^{17}$ seems to show the predominant role of resonance interaction of the alkyl groups in the excited states of these molecules. An earlier investigation by Rao, Goldman and Lurie ${ }^{18}$ of the infra-red carbonyl frequencies in aliphatic ketones had indicated that mainly inductive effects were important in the ground-states of these molecules.

The chemical evidence for hyperconjugation has been a subject of controversy. The Baker-Nathan order $\mathrm{Me}>\mathrm{Et}>i$ - $\mathrm{Pr}>t-\mathrm{Bu}$, has been found in a number of reactions and has been explained in terms of the $\mathrm{C}-\mathrm{H}$ hyperconjugation ${ }^{19}$. The importance of $\mathrm{C}-\mathrm{C}$ hyperconjugation in the $t$-butyl group has also been pointed out ${ }^{20}$. The relative importance of $\mathrm{C}-\mathrm{H}$ and $\mathrm{C}-\mathrm{C}$ hyperconjugation in aliphatic and aromatic series has been evaluated by the application of the linear inductive energy relationship 21,22 McCaulay and $\mathrm{Lien}^{23}$ have shown that $\mathrm{C}-\mathrm{H}$ hyperconjugation must be an important mode of electron release in the methyl-substituted aromatic cations. De la Mare $^{24}$ has discussed the possibility of $\mathrm{OH}$ and NH hyperconjugation. Shiner ${ }^{25}$, Lewis ${ }^{26}$ and Taft and co-workers' ${ }^{27}$ have shown that hypercon- 
jugation is one of the important sources of secondary isotope effects. Shiner ${ }^{25}$ considers three possible effects on hyperconjugation: steric, substituent and solvent effects. Brown ${ }^{28}$ has recently discussed the relative importance of the dispersion and induction forces in alkyl benzenes. Berliner ${ }^{19}$ is of the opinion that although the effect of the alkyl groups in individual reactions can be interpreted in different ways (based on solvent or steric or inductive effects), hyperconjugation appears to be the most satisfactory general explanation for the behaviour of remote alkyl groups on the benzene ring where the BakerNathan order is observed.

The information from chemical reactivity regarding the possible role of hyperconjugation is not consistent, and does not distinguish such a contribution in the ground-state from that in the transition state of the molecule. Further, there is no clear evidence for any marked degree of hyperconjugation from physical messurements on the ground-states of molecules. These arguments have been forcefully expressed by Dewar and Schmeising ${ }^{29}$, who have developed a new method for calculating bond-lengths and resonance energies for conjugated systems taking the $\sigma$-bond compression into consideration. They argue that if the $\pi$-electron resonance is unimportant in ordinary conjugation (as in the case of butadiene), it should be much more so in hyperconjugation. But Mulliken ${ }^{30}$ has found it desirable explicitly to classify conjugation and hyperconjugation into two types : isovalent and sacrificial (ordinary). $\mathrm{He}$ also suggests further classification of isovalent conjugation and isovalent hyperconjugation into sub-types. Isovalent hyperconjugation has been suggested as being more important than ordinary hyperconjugation. The Baker-Nathan effect has been described as differential hyperconjugation. Apparently there are no theoretical reasons for expecting differences between $\mathrm{C}-\mathrm{C}$ and $\mathrm{C}-\mathrm{H}$ hyperconjugation ${ }^{30}$.

In my view, the present status of hyperconjugation may be summarized as follows: while the contribution from hyperconjugation seems unimportant in the electronic ground-states of molecules, it may be prominent in the excited or the transition states of molecules.

I have benefited greatly from stimulating discussions with colleagues in Purdue University and the University of California. Many of the papers referred to as appearing in Tetrahedron were published in a special issue of that journal containing the proceedings of a Conference on Hyperconjugation held at Indiana University in June 1958. C. N. R. RAO*

* Department of Inorganic and Physical Chemistry, Indian Institute of Seience, Bangalore.

${ }^{1}$ Mulliken, R. S., Reike, C. A., and Brown, W. G., J. Amer, Chem. Soc., 63, 41 (1941).

${ }^{2}$ Kiedel, F. A., and Bauer, S. H., J. Chem. Phys., 25, 1218 (1956).

${ }^{3}$ Zeil, W., and Pfrommer, J. F., Z. Elektrochem., 61, 938 (1957).

"Coulson, C. A. "Valence" (Clarendon Press, Oxford, 1952).

"Baker, J. W., "Hyperconjugation" (Oxford Univ. Press, 1953).

"Matsen, F. A., Robertson, W. W., and Chuoke, R. L., Chem. Revs, 41, $273(1947)$.

Muller, N., and Pritchard, D. E., J. Amer. Chem. Sam., 80, $348: 3$ $(1958)$.

${ }^{8}$ Sutton, L. E., Tetrahedron, 5, 118 (1959).

- Turner, R. B., Tetrahedron, 5, 127 (1959).

${ }^{10}$ Petro, A. J., J. Amer. Chem. Soc., 80, 4230 (1958).

"11 Brown, T. L., J. Amer. Chem. Soc., 81, 3232 (1959).

${ }^{12}$ Hammond, V. J., Price, W. C., Teegan, J. P., and Walsh, A. D. Discuss. Farad. Soc., 9 , 53 (1950).

${ }^{13}$ Streitwieser, jun., A., and Nair, P. M., Tetrahedron, 5, 149 (1959).

${ }_{14}$ Platt, J. R., and Klevens, H. B., Chem. Revs., 41, 301 (1947).

${ }^{15}$ Bowden, K., and Braude, K. A., J. Chem. Soc., 1068 (1952).

${ }^{16}$ Schubert, W. M., Craven, J. M., Minton, R. G., and Murphy, R. B.. Tetrahedron, 5, 194 (1959).

${ }^{17}$ Rao, C. N. R., et al., Tetrahedron Letters, 2 (1960); Canad. J. 1 .hem. and Chem. Indust. (in the press).

${ }^{13}$ Rao, C. N. R., Goldman, G. K., and Lurie, C., J. Phys. Chem., 63 1311 (1959)

19 Berliner, E., Tetrahedron, 5, 202 (1959).

${ }^{20}$ Brown, H. C., Brady, J. D., Grayson, M., and Bonuer, W. H. J. Amer. Chem. Soc, $\mathbf{7 9}, \mathbf{1 8 9 7}$ (1957).

${ }^{21}$ Taft, jun., R. W., and Lewis, I. C., Tetrahedron, 5, 210 (1959)

22 Baker, J. W., Tetrahedron, 5, 135 (1959).

${ }^{23}$ McCaulay, D. C., and Lien, A. P., Tetrahedron, 5, $186(1959)$.

${ }^{24}$ De la Mare, P. B. D., Tetrahedron, 5, 107 (1959).

${ }^{25}$ Shiner, jun, V. J., Tetrahedron, 5, 243 (1939).

${ }^{26}$ Lewis, E. S., Tetrahedron, 5, 143 (1959).

${ }^{22}$ Love, P., Taft, ;jun., R. W., and Wartik, T., Tetrahedron, 5,11 (1) (1959). ${ }_{28}^{8}$ Brown, T. L., J. Amer. Chem. Soc., 81, 3229 (1959).

${ }^{20}$ Dewar, M. J. S., and Schmeising, H. N., Tetrahedron, 5, 16it +1959).

${ }^{3}{ }_{0}$ Mulliken, R. S., Tetrahedron, 5, 253 (1959).

\title{
THE 'GBR EXPERIMENT': A TRANS-ATLANTIC FREQUENCY COMPARISON BETWEEN CAESIUM-CONTROLLED OSCILLATORS
}

\author{
By J. A. PIERCE \\ Cruft Laboratory, Harvard University, Cambridge, Mass. \\ G. M. R. WINKLER \\ U.S. Army Signal Research and Development Laboratory, Ft. Monmouth, New Jersey \\ AND \\ R. L. CORKE \\ Post Office Research Branch, Dollis Hill, London, N.W.2
}

$\mathrm{F}^{\mathrm{o}}$ OR several years the temporal variation of phase, and hence the frequency, of a $16-\mathrm{kc} . / \mathrm{s}$. signal from Rugby, England, has been observed at Cambridge, Massachusetts ${ }^{1,2}$. During this period the transmission has been controlled by an Essen ring crystal oscillator and the reference at Cambridge has been one of several crystals or, since early 1958, an Atomichron.

The problem of resolving the observed fluctuations of phase into components caused on the propagation. path and those produced by one or both oscillators has been attacked by choosing short periods (usually
4 or 5 days) when operation seemed especially stablo. For these short lengths of time, internal evidence seemed to indicate that the oscillators were behaving in a consistent way and the observed deviations were taken as representing primarily variations in transmission time. The results of this somewhat dubious procedure indicated standard deviations of phase of about 1 or 2 usec. When observations were extended over $24 \mathrm{hr}$., the corresponding precision of frequency measurement should have been about two parts in $10^{11}$ 